\title{
In Vitro Nucleoside Specific Immune Response by Lymphocytes from Systemic Lupus Erythematosus
}

\author{
Chikao Morimoto, Alfred D. Steinberg, Stuart F. Schlossman, and \\ Yves BOREL, Division of Tumor Immunology, Sidney Farber Cancer \\ Institute, Children's Hospital Medical Center, Department of Medicine and \\ Pediatrics, Harvard Medical School, Boston, Massachusetts 02115; Arthritis \\ Branch, National Institute of Arthritis, Diabetes, Digestive and Kidney \\ Diseases, National Institutes of Health, Bethesda, Maryland 20205
}

A B STRACT The in vitro immune response of systemic lupus erythematosus (SLE) lymphocytes to nucleosides conjugated to keyhole limpet hemocyanin (KLH) (A,G,C,T-KLH) was investigated. The nucleosides were chosen not only because they are a part of nucleic acid antigen and involved in autoimmunity, but also because nucleoside covalently bound to either soluble IgG or cells had been shown to induce unresponsiveness in mice. A significant proliferation index was induced in SLE lymphocytes, as compared with normal or rheumatoid arthritis (RA) lymphocytes in vitro [in (A,G,C,T)-KLH, $1 \mu \mathrm{g} / \mathrm{ml}$; stimulation index $=\mathrm{M} \pm \mathrm{SE}$, SLE $2.10 \pm 0.26$, RA $1.06 \pm 0.14$, normal $1.12 \pm 0.12 P<0.05$ ]. Lymphocytes from SLE patients responded specifically to low doses of $(A, G, C, T)-K L H$ and not to the protein carrier KLH alone. A solid-phase radioimmunoassay was developed to detect nucleoside-specific antibody. SLE lymphocytes spontaneously produced high levels of anti-A,G,C,T antibody. This was further increased by antigenic stimulation, but not with pokeweed mitogen (PWM) stimulation. In contrast normal lymphocytes failed to produce anti-A,G,C,T antibody either spontaneously or in response to antigen. However, normal lymphocytes produced antibody after stimulation with PWM.

More importantly, anti-A,G,C,T antibody production by SLE lymphocytes was suppressed by preincubation with A,G,C,T-IgG (A,G,C,T-HGG). The antigen-specific unresponsiveness caused by A,G,C,THGG was demonstrated by the observation that

This work was presented in part at the VII Pan-American Congress of Rheumatology in Washington, DC, 11 June 1982.

Dr. Morimoto is a recipient of a postdoctoral fellowship award from the Arthritis Foundation.

Received for publication 25 October 1982 and in revised form 19 January 1983. preincubation with A,G,C,T-HGG did not affect the production of anti-dinitrophenyl antibody response. The ability to manipulate the altered response of SLE lymphocytes to nucleic acid antigens may have therapeutic implications in these patients.

\section{INTRODUCTION}

Systemic lupus erythematosus (SLE) ${ }^{1}$ has long been considered a prototypic autoimmune disease because of its multisystem involvement and the production of multiple antibodies. A typical lupus serum can react with nucleic acid (native or denatured DNA, RNA) nucleoprotein (Sm and RNP antigens; ribosomes; nucleohistones) and cell surface antigens (1). Antibodies to nucleic acids are particularly significant since the deposition of immune complexes of antinucleic acid antibodies with nucleic acid antigens is considered to be an important pathogenetic mechanism in SLE (2-5).

Previous studies have suggested that some of these immune abnormalities found in patients with active SLE may result from loss of suppressor $T$ cells and/or abnormalities in their function (6-10). However, those

\footnotetext{
${ }^{1}$ Abbreviations used in this paper: A, adenosine; BPOHGG, benzyl penicilloyl linked to human $\gamma$-globulin; BPO$\mathrm{KLH}$, benzyl penicilloyl linked to keyhole limpet hemocyanin; (A,G,C,T)-BSA, all four nucleosides conjugated to bovine serum albumin; $C$, cytidine; DNP-BSA, dinitrophenyl linked to bovine serum albumin; DNP-KLH, dinitrophenyl linked to keyhole limpet hemocyanin; FCS, fetal calf serum; G, guanosine; HGG, human $\gamma$-globulin; (A,G,C,T)-HGG, all four nucleosides conjugated to human $\gamma$-globulin; (A,G,C,T) $\mathrm{KLH}$, a conjugate in which all four nucleosides are coupled simultaneously keyhole limpet hemocyanin (KLH); RA, rheumatoid arthritis; PWM, pokeweed mitogen; SI, stimulation index; SLE, systemic lupus erythematosus; T, ribothymidine.
} 
studies did not examine regulation of antibodies specific for nucleic acid determinants. In the present study, we investigated the in vitro response of SLE lymphocytes to nucleoside conjugated to keyhole limpet hemocyanin (KLH) (A,G,C,T-KLH). The nucleosides were chosen not only because they were part of nucleic acid antigens and involved in autoimmunity, but also because nucleoside covalently bound to either soluble IgG or cells had been shown to induce unresponsiveness in experimental animals $(11,12)$. The results described herein demonstrate that SLE lymphocytes proliferate in response to nucleoside carrier conjugate, make nucleoside-specific antibody, and can be rendered tolerant with regard to nucleoside antibody formation in vitro with $(A, G, C, T)$ human gamma globulin (HGG) (the nucleosides conjugated to human $\gamma$-globulin).

\section{METHODS}

Antigens. HGG was isolated from the pooled sera over a DEAE-column using a $0.01 \mathrm{M}, \mathrm{pH} 6.8$ phosphate-eluting buffer. KLH was obtained from Calbiochem-Behring Corp., Div. American Hoechst Corp., San Diego, CA, and was prepared as described elsewhere (13). Nucleoside was conjugated to HGG, bovine serum albumin (BSA), or KLH by the procedure of Erlanger and Beiser as described previously (14). The hapten-carrier conjugates used in this experiment are the following: $(\mathrm{A}, \mathrm{G}, \mathrm{C}, \mathrm{T})_{49}-\mathrm{KLH},(\mathrm{A}, \mathrm{G}, \mathrm{C}, \mathrm{T})_{14}-\mathrm{HGG}$, $(\mathrm{A}, \mathrm{G}, \mathrm{C}, \mathrm{T})_{14}$-BSA, DNP ${ }_{257}-\mathrm{KLH}, \mathrm{DNP}_{15}$-BSA, BPO 11 -HGG and $\mathrm{BPO}_{56}-\mathrm{KLH}$. In each case, the subscript indicates the total molar ratio of hapten substitution on the carrier protein.

Isolation of lymphoid populations. Human peripheral blood mononuclear cells were isolated from heparinized venous blood by Ficoll-Hypaque (Pharmacia Fine Chemicals, Inc., Piscataway, NJ) density centrifugation.

Patients. 36 patients with SLE satisfying the diagnostic criteria of the American Rheumatism Association and seven patients with a classic or definite RA were studied. Blood was also obtained from 10 normal volunteers of similar age and sex. All patients were monitored at the Children's Hospital Medical Center in Boston and at the Arthritis Branch of the National Institute of Arthritis, Diabetes, Digestive and Kidney Disease in Bethesda. Clinical activity was assessed at the time of blood drawing by the physicians on the basis of signs and symptoms (active rash, serositis, arthritis, active central nervous system disease, and active renal disease). Patients lacking these symptoms or detectable signs of activity were categorized as inactive. The active patients in this study had at least two of the above criteria of activity. When the in vitro studies were done, the disease activity was not informed.

Proliferative studies. Cell suspensions were cultured at a final concentration of $1 \times 10^{6}$ cells $/ \mathrm{ml}$ in RPMI 1640 supplemented with $10 \%$ AB serum, $200 \mathrm{mM}$ L-glutamine, 25 $\mathrm{mM}$ Hepes buffer, $0.5 \%$ sodium bicarbonate, and $1 \%$ penicillin-streptomycin. $0.2-\mathrm{ml}$ aliquots of cell suspensions containing the indicated doses of antigens were distributed into the wells of round-bottomed microtiter plates (Falcon Labware, Div. Becton, Dickinson Co., Oxnard, CA). Cultures were made in triplicate, incubated at $37^{\circ} \mathrm{C}$ in a humid atmosphere of $5 \% \mathrm{CO}_{2}$ in air for $5 \mathrm{~d}$, pulsed with $0.2 \mu \mathrm{Ci}$ $\left[{ }^{3} \mathrm{H}\right]$ thymidine (1.9 Ci/mM sp act) (Schwartz/Mann Div.,
Becton, Dickinson Co., Orangeburg, NY) and harvested 18 h later on a MASH II apparatus (Microbiological Associates, Bethesda, MD). Results were expressed as stimulation indexes (SI) where: SI = (count per minute incorporated by antigen-stimulated culture)/(counts per minute incorporated by control-unstimulated culture).

Anti-A,G,C,T antibody formation in vitro. Culture conditions for anti-A,G,C,T antibody formation were the same as previously described (15) for the anti-DNP antibody response. Briefly, peripheral blood lymphocytes were cultured for $5 \mathrm{~d}$ with the indicated concentration of antigens or with PWM in a total volume of $200 \mu \mathrm{l}$ per well in flat-bottomed microtiter plates (Falcon Labware) in RPMI 1640 supplemented with $20 \%$ fetal calf serum (FCS) (Grand Island Biological Co., Grand Island, NY), $200 \mathrm{mM}$ L-glutamine, $25 \mathrm{mM}$ Hepes buffer, $0.5 \%$ sodium bicarbonate, and $1 \%$ penicillin-streptomycin at $37^{\circ} \mathrm{C}$ in a humid atmosphere containing $5 \% \mathrm{CO}_{2}$.

At the completion of the culture period, the cells were washed three times to remove antigen, resuspended in the same media, and incubated for 5 additional d at $37^{\circ} \mathrm{C}$. Culture supernatants from five individual wells were pooled and stored at $-20^{\circ} \mathrm{C}$ until assayed for anti-A, G,C,T antibody.

Tolerance induction in vitro. Peripheral blood lymphocytes $(\mathrm{PBL})\left(4 \times 10^{6} / \mathrm{ml}\right)$, resuspended in the supplemented RPMI 1640 media described above were incubated with or without $10 \mu \mathrm{g} / \mathrm{ml}$ of (A,G,C,T)-HGG or $10 \mu \mathrm{g}$ of control antigens as indicated in Linbro 24-flat-bottomed wells (Flow Laboratories, Maler, VA) at $37^{\circ} \mathrm{C}$ in $5 \% \mathrm{CO}_{2}$ for $18 \mathrm{~h}$. Cells were then harvested, washed three times and resuspended in the supplemented media. PBL $\left(4 \times 10^{6} / \mathrm{ml}\right)$, precultured with (A,G,C,T)-HGG were subsequently cultured with 1 $\mu \mathrm{g} / \mathrm{ml}(\mathrm{A}, \mathrm{G}, \mathrm{C}, \mathrm{T})-\mathrm{KLH}$ in a total volume of $200 \mu \mathrm{l}$ per well in flat-bottomed microtiter plates for the production of antiA,G,C,T antibody as described above.

Radioimmunoassay for anti-A,G,C,T antibody. The radioimmunoassay (RIA) used for measurement of anti-A,G,C,T antibody in culture media was a solid phase RIA technique as described previously $(15,16)$. Briefly, (A,G,C,T)-BSA was absorbed onto flexible polyvinyl plates (Cooke Laboratory Products, Alexandria, VA) at a concentration of $1 \mathrm{mg} / \mathrm{ml}$ for $2 \mathrm{~h}$ at $4^{\circ} \mathrm{C}$. After excess (A,G,C,T)-BSA was removed, the wells were thoroughly washed and any further nonspecific binding sites were blocked by incubation with $1 \%$ BSA in phosphate-buffered saline. After additional washing, 50 $\mu l$ of culture supernatants were added to each well, incubated for $3 \mathrm{~h}$ at $4^{\circ} \mathrm{C}$ and washed three times.

Finally, $25 \mu \mathrm{l}$ containing $10^{5} \mathrm{cpm}$ of ${ }^{125}$ I-labeled (chloramine $T$ method) affinity purified, rabbit anti-human $\mathrm{F}\left(\mathrm{ab}^{\prime}\right)_{2}$ were added to each well. The plates were incubated overnight at $4^{\circ} \mathrm{C}$. Unbound ${ }^{125} \mathrm{I}$ was removed by extensive washing, the plates were cut with scissors, and each well was counted for bound radioactivity in a gamma counter. AntiA,G,C,T antibody production secreted into culture supernatants was assayed in triplicate. Background values determined by replacing the second layer culture supernatants with $20 \%$ FCS in RPMI 1640 , were usually $<200 \mathrm{cpm}$ and were subtracted from experimental values.

Determination of Ig classes of anti-A,G,C,T antibody. The monospecific anti-human IgM and anti-human IgG sera were purchased from Miles Laboratories, Inc., Elkhart, IN, and further purified by elution from appropriate immunoabsorbent columns. These antisera were then coupled to BrCN activated Sepharose $4 \mathrm{~B}$ as outlined by the manufacturer (Pharmacia Fine Chemicals). To determine the Ig classes of the anti-A,G,C,T antibodies, a culture supernatant aliquot was passed through a column of Sepharose 4B cou- 
pled with one of another antiserum, and subsequently, the anti-A,G,C,T antibody activity of the eluate was compared to the anti-A,G,C,T activity of an aliquot of culture supernatant that was passed through a column of uncoupled, unactivated Sepharose 4B.

\section{RESULTS}

Antigen-induced proliferation of $P B L$ in vitro. (A,G,C,T)-KLH induced proliferation by PBL from patients with SLE and RA and from normal individuals was studied. Significantly greater stimulation of SLE PBL was observed at low doses of antigen (Fig. 1). The mean $\pm \mathrm{SE}$, SI at $1 \mu \mathrm{g} / \mathrm{ml}$ were SLE $2.10 \pm 0.26$, RA $1.06 \pm 0.14$, normal $1.12 \pm 0.12(P<0.05)$. The differences were also significant at $0.1 \mu \mathrm{g} / \mathrm{ml}$, however they were not at $10 \mu \mathrm{g} / \mathrm{ml}$. Lymphocytes from SLE patients responded specifically to low doses of $(A, G, C, T)-K L H$ and not to the protein carrier KLH alone (Fig. 1). 10 $\mu \mathrm{g} / \mathrm{ml}$ of either (A,G,C,T)-KLH or KLH led to good responses in normals and $\mathrm{RA}$ patients, as well as in SLE patients.

In vitro $A, G, C, T$ antibody response of patients with SLE. To determine the optimal conditions for antiA,G,C,T antibody production, varying amounts of (A,G,C,T)-KLH were added to $0.2 \mathrm{ml}$ of media containing $8 \times 10^{5} \mathrm{PBL}$. SLE lymphocytes produced high levels of anti-A,G,C,T antibody without stimulation, the maximal antibody response was observed at an antigen concentration of 0.1 or $1 \mu \mathrm{g}$ per ml. Lymphocytes from normal individuals failed to produce antiA,G,C,T antibody (anti-A,G,C,T antibody ranges of 10 normal individuals are shown in the shaded area

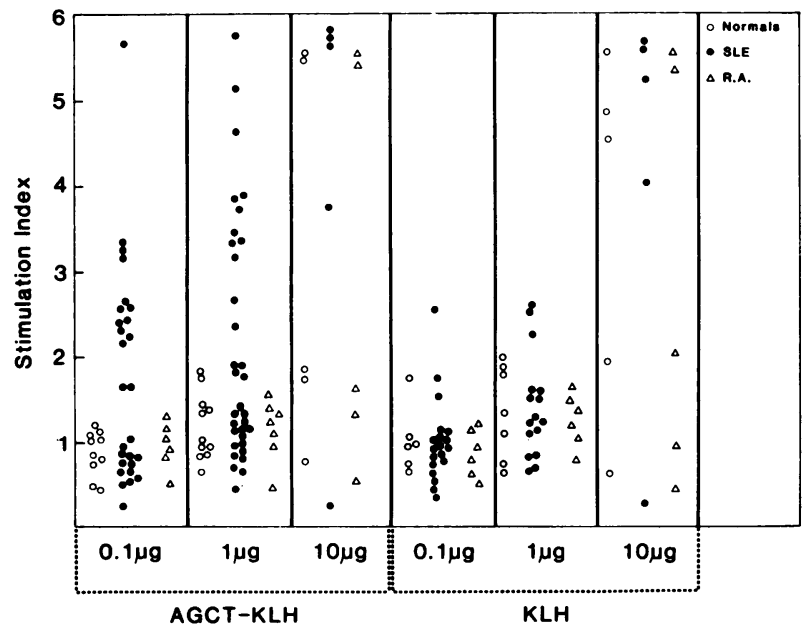

Figure 1 (A,G,C,T)-KLH induced proliferation by PBL from patients with SLE, RA, and normals. SI, counts per minute incorporated by antigen stimulated culture/counts per minute incorporated by control unstimulated culture. O, normal; •, SLE; $\triangle$, RA. in Fig. 2) either spontaneously or in response to antigen. Thus, whereas normal lymphocytes could proliferate in regard to high doses of $(\mathrm{A}, \mathrm{G}, \mathrm{C}, \mathrm{T}) \mathrm{KLH}$, they could not produce antibody in response to that antigen.

$P W M$ stimulated $A, G, C, T$ responses of normal and SLE lymphocytes. Fig. 3 compares the high spontaneous anti-A,G,C,T responses that were observed from SLE lymphocytes $(7,020 \pm 850 \mathrm{cpm})$ with the minimal response by normal lymphocytes $(268 \pm 80 \mathrm{cpm})$. After stimulation with PWM, the anti-A,G,C,T response by SLE lymphocytes was decreased to $4,210 \pm 542 \mathrm{cpm}$. In contrast, an increased amount of anti-A,G,C,T antibody was secreted by the normal lymphocytes $(2,240 \pm 356 \mathrm{cpm})$.

Relationship between nucleoside specific immune response and disease activity of SLE. Furthermore, the relationship between nucleoside specific immune response and disease activity of SLE was examined. As shown in Table I, the patients with active SLE had both a higher stimulation index of antigen induced lymphocyte proliferation and higher spontaneous anti$A, G, C, T$ antibody production than patients with inactive SLE.

Specificity of the anti-A,G,C,T antibody produced. We investigated the ability of soluble $(A, G, C, T), D N P$ BSA, or OA to inhibit anti-A,G,C,T antibody binding to AGCT-coated plates. After in vitro culture, $(A, G, C, T), D N P-B S A$, or OA were added to the culture

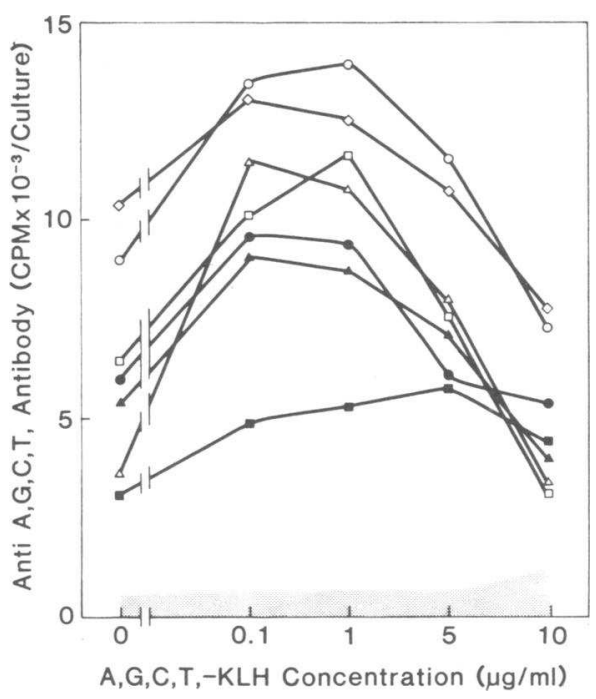

Figure 2 Optimal antigen concentration for anti-A,G,C,T antibody production. PBL $\left(8 \times 10^{5} /\right.$ culture $)$ were cultured with different concentrations of A,G,C,T)-KLH. Results are representative experiments from different donors. Values are expressed as mean of triplicate samples. Standard errors are within $10 \%$. Anti-A,G,C,T antibody ranges of 10 normal individuals are shown in the shaded area. 


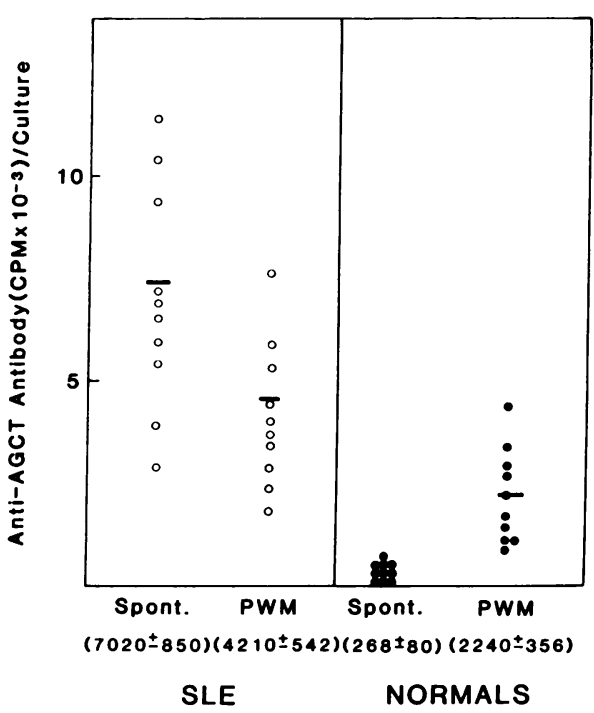

Figure 3 Spontaneous and PWM-stimulated A,G,C,T responses of lymphocytes from patients with SLE and normals. The means are indicated by the short horizontal lines. Values are the mean $\pm S E$.

supernatants before their addition to plastic plates previously coated with (A,G,C,T)-BSA. The supernatants were removed and the plates were washed several times before the addition of ${ }^{125}$ I-labeled rabbit antihuman $F\left(a b^{\prime}\right)_{2}$. As shown in Table II, addition of $(A, G, C, T)$ to the culture supernatant resulted in a marked decrease in antibody binding while the addition of DNP-BSA or OA resulted in only minimal inhibition of anti-A,G,C,T antibody binding. These results suggest that the antibody produced was $A, G, C, T$ specific.

Characterization of anti-A,G,C,T antibody class. To determine the class of anti-A,G,C,T antibody-pro-

TABLE I

Relationship between Nucleoside-specific Immune Response and Disease Activity of SLE

\begin{tabular}{lcc}
\hline & $\begin{array}{c}\text { Stimulation } \\
\text { index }\end{array}$ & $\begin{array}{c}\text { Anti-A,G,C,T } \\
\text { antibody }\end{array}$ \\
\hline $\begin{array}{l}\text { A Antigen-induced proliferation } \\
\text { (A,G,C,T-KLH }=1 \mu \mathrm{g} / \mathrm{ml})\end{array}$ & & \\
Active SLE (17) & & \\
Inactive SLE (16) & $2.89 \pm 0.36 \ddagger$ & - \\
B Spontaneous anti-A,G,C,T response & $1.22 \pm 0.17$ & - \\
Active SLE (6) & - & $8,850 \pm 981 \S$ \\
Inactive SLE (4) & - & $4,575 \pm 879$ \\
\hline
\end{tabular}

- Parentheses show the number of patients studied.

$\ddagger$ Results are mean \pm SE. $P<0.001$.

$\S$ Results are mean counts per minute/culture \pm SE. $P<0.05$.
TABLE II

Specificity of the Anti-A,G,C,T Antibody Produced ${ }^{\circ}$

\begin{tabular}{cccrc}
\hline $\begin{array}{c}\text { Exp. } \\
\text { no. }\end{array}$ & Media (control) & A,G,C,T & OA & DNP-BSA \\
\hline 1 & $8,500 \pm 5701$ & $1,100 \pm 100$ & $8,200 \pm 400$ & $7,400 \pm 550$ \\
2 & $11,000 \pm 880$ & $1,200 \pm 90$ & $10,500 \pm 740$ & $9,900 \pm 670$ \\
3 & $7,900 \pm 400$ & $900 \pm 80$ & $8,000 \pm 570$ & $7,500 \pm 490$ \\
4 & $9,400 \pm 730$ & $1,050 \pm 130$ & $9,200 \pm 780$ & $8,400 \pm 420$ \\
\hline
\end{tabular}

- After in vitro culture, $25 \mu \mathrm{l}$ of A,G,C,T ( $1 \mathrm{mg} / \mathrm{ml})$, DNP-BSA $(1 \mathrm{mg} / \mathrm{ml})$, or $O A(1 \mathrm{mg} / \mathrm{ml})$ were added to the $50 \mu \mathrm{l}$ of culture supernatants before their addition to plastic plates previously coated with (A,G,C,T)-BSA. As a control, $25 \mu$ l of Hanks' buffer were added to the culture supernatants.

$\ddagger$ Values are expressed as the mean counts per minute/culture $\pm \mathrm{SE}$ of triplicate samples.

duced culture supernatants were passed through both anti-human IgM and anti-IgG conjugated Sepharose 4B columns and the eluate was examined for residual anti-A,G,C,T antibody activity by RIA. As a control, the culture supernatants were also passed through an unconjugated Sepharose 4B column. SLE supernatants were from A,G,C,T-stimulated cultures. Normals did not produce enough antibody following (A,G,C,T)KLH stimulation for such an analysis. Therefore, PWM-induced antibody from normals was studied. Table III shows that in PWM-stimulated normal culture supernatants, an anti-IgM column could remove $>80 \%$ of the anti-A,G,C,T antibody binding activity, whereas an anti-IgG column had a minimal effect. In contrast, in A,G,C,T stimulated culture supernatants of SLE, an anti-IgG column could remove $>60 \%$ of the anti-A,G,C,T antibody binding activity, whereas the anti-IgM column removed less anti-A,G,C,T antibody binding activity. These results demonstrate that anti-A,G,C,T antibody produced by SLE lymphocytes was predominantly of the IgG isotype and that antiA,G,C,T antibody produced by normals after stimulation with PWM was primarily of the IgM isotype.

$A, G, C, T$-specific inhibition of antibody production by preincubation with A,G,C,T-HGG conjugates. The effect of in vitro incubation of lymphocytes with various conjugates on the anti-A,G,C,T antibody response was assessed in the SLE patients whose lymphocytes produced a large amount of anti-A,G,C,T antibody. As shown in Fig. 4, lymphocytes preincubated without antigen produced $12,000 \pm 900 \mathrm{cpm}$ of antiA,G,C,T antibody. In contrast, preincubation with (A,G,C,T)-HGG (line 6) resulted in significant (66\%) suppression of the anti-A,G,C,T response $(4,100 \pm 600$ cpm). Preincubation with unconjugated HGG or $A, G, C, T$ or $(A, G, C, T)-K L H$ or BPO-HGG or BPOKLH failed to inhibit anti-A,G,C,T antibody response. 
TABLE III

Characterization of Anti-A,G,C,T Antibody

\begin{tabular}{cccc}
\hline Culture supernatant & Sepharose 4B absorbed & IgM absorbed & IgG absorbed \\
\hline $\begin{array}{c}\text { A PWM-stimulated normal } \\
\text { lymphocytes }\end{array}$ & & & \\
1 & $4,640 \pm 150$ & $510 \pm 30$ & $4,150 \pm 180$ \\
2 & $3,430 \pm 130$ & $750 \pm 50$ & $3,350 \pm 110$ \\
3 & $4,100 \pm 240$ & $680 \pm 50$ & $3,920 \pm 190$ \\
B AGCT-KLH-triggered SLE & & & \\
lymphocytes & & & \\
1 & $8,490 \pm 490$ & $4,950 \pm 180$ & $3,420 \pm 260$ \\
2 & $7,740 \pm 340$ & $6,140 \pm 270$ & $2,850 \pm 120$ \\
3 & $9,470 \pm 450$ & $5,900 \pm 340$ & $3,370 \pm 310$ \\
\hline
\end{tabular}

- Culture supernatants were passed through affinity purified goat anti-human IgM and antiIgG conjugated Sepharose 4B columns. As a control, culture supernatants were passed through a Sepharose 4B column.

Values are expressed as the mean counts per minute/culture $\pm \mathrm{SE}$ of triplicate samples.

In addition to this, preincubation with A,G,C,T-human serum albumin did not show any suppression of antiA,G,C,T response (Table IV). These results suggest that preincubation with (A,G,C,T)-HGG can induce hapten $(\mathrm{A}, \mathrm{G}, \mathrm{C}, \mathrm{T})$-specific tolerance in vitro. To determine whether (A,G,C,T)-HGG causes specific unresponsiveness, the anti-DNP response of these tolerizing cells was also examined (Fig. 5). Although preincubation with (A,G,C,T)-HGG did not affect the production of anti-DNP antibody response, the anti-A,G,C,T antibody response was inhibited. As expected, preincu- bation with (A,G,C,T)-KLH or BPO-HGG did not affect either the anti-A,G,C,T response or the anti-DNP response. These results demonstrate that the suppression of the anti-A,G,C,T response was antigen specific.

\section{DISCUSSION}

In the present study, spontaneous nucleoside specific antibody production by SLE lymphocytes was observed. The quantity of antibody secreted was increased by antigenic stimulation with a nucleoside car-

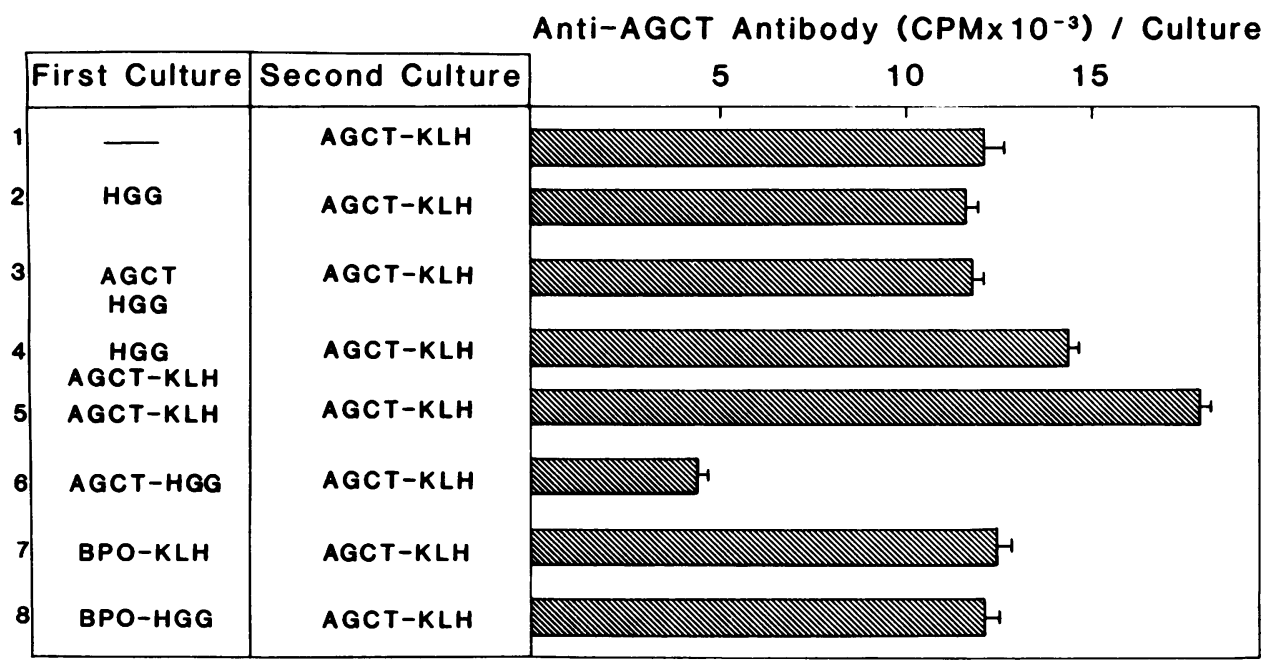

FIgURE 4 Hapten-specific tolerance induction in vitro. PBL from patients with SLE preincubated with (A,G,C,T)-HGG or indicated antigens were cultured with (A,G,C,T)-KLH for anti-A,G,C,T response. Results are representative of four individual experiments performed. Values are expressed as mean counts per minute/culture $\pm \mathrm{SE}$ of triplicate samples. 
TABLE IV

Human IgG-dependent Tolerance Induction In Vitro

\begin{tabular}{clc}
\hline Lymphocytes preincubated with & \multicolumn{1}{c}{ Exp. 1 } & Exp. 2 \\
\hline & $6,500 \pm 340 \pm$ & $8,700 \pm 650$ \\
A,G,C,T-HGG & $3,800 \pm 190$ & $4,800 \pm 410$ \\
A,G,C,T-HSA & $6,100 \pm 310$ & $8,900 \pm 710$ \\
\hline
\end{tabular}

- Lymphocytes from SLE preincubated with indicated antigens or media were cultured with $(A, G, C, T)-K L H$ for anti-A,G,C,T response.

I Values are expressed as mean counts per minute/culture $\pm \mathrm{SE}$ of triplicate samples.

rier conjugate, (A,G,C,T)-KLH. Furthermore, antiA,G,C,T-specific antibody production by lymphocytes from SLE was suppressed by preincubation with A,G,C,T IgG (A,G,C,T-HGG). The antigen-specific unresponsiveness caused by (A,G,C,T)-HGG was demonstrated by the observation that preincubation with (A,G,C,T)-HGG did not affect the production of antiDNP antibody response. SLE lymphocytes, but not normal and RA lymphocytes, proliferated in response to stimulation by low doses $(0.1$ or $1.0 \mu \mathrm{g} / \mathrm{ml})$ of (A,G,C,T)-KLH. This result is consistent with studies demonstrating that SLE lymphocytes had sensitized to nuclear antigen $(17,18)$. In other studies, SLE lymphocytes cultured with native DNA produced a macrophage migration inhibitory factor that also suggests that there are circulating DNA-sensitized lymphocytes (19).

SLE lymphocytes spontaneously produced high levels of anti-A,G,C,T antibody. This was further increased by antigenic stimulation, but not PWM stimulation. In contrast, normal lymphocytes produced antibody only after stimulation with PWM. The spon- taneous high production of anti-A,G,C,T by SLE lymphocytes is consistent with studies demonstrating that lymphocytes from active SLE produced spontaneously large quantities of immunoglobulin in vitro and an increased number of $B$ cells defined by monoclonal anti-Bl (20-22). These include autoantibodies, such as DNA, and antibodies to specificities thought to be unrelated to self antigens such as trinitrophenyl (2326). It is also reported that lymphocytes from SLE patients had a markedly depressed in vitro response to PWM with regad to Ig synthesis $(21,27)$. Similarly, the A,G,C,T-specific antibody response by SLE lymphocytes was decreased following stimulation with PWM. This greater stimulation index of SLE lymphocytes as well as the spontaneous high levels of antiA,G,C,T antibody by SLE lymphocytes were correlated well with disease activity.

After polyclonal stimulation by $\mathrm{PWM}$, an increased amount of anti-A,G,C,T antibody was obtained from cultures of normal lymphocytes. The immunoglobulin class of the anti-A,G,C,T antibody produced by normal lymphocytes belongs mainly to the IgM class, antiA,G,C,T antibody produced by SLE lymphocytes was predominantly IgG. In this regard, Bankhurst et al. showed that normal individuals had DNA binding lymphocytes but that they occurred in smaller numbers than in SLE (23). More recently, it has been reported that after Epstein-Barr virus transformation, normal B cells can produce DNA antibody although these lymphocytes did not produce such antibody spontaneously (28). Our results suggest that normal lymphocytes contain precursors of B cells capable of producing anti-nucleoside antibody. Further studies are needed to define the fine specificity of the antinucleoside antibody in the culture supernatant utilizing either isolated nucleosides, polynucleosides, or single-stranded DNA.

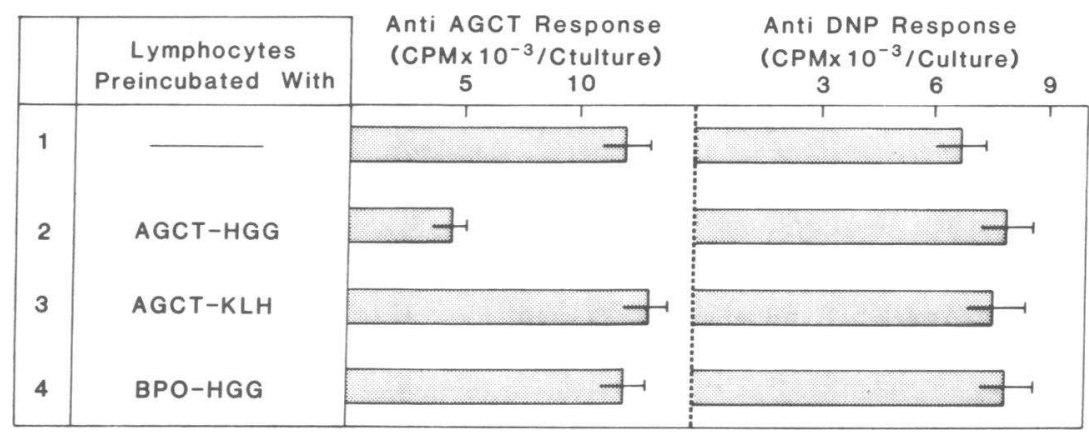

FIGURE 5 Antigen specificity of hapten-specific tolerance. To determine whether (A,G,C,T)HGG causes specific unresponsiveness, the anti-DNP response of lymphocytes preincubated with (A,G,C,T)-HGG was also examined. Results are representative of four individual experiments performed. Values are expressed as mean counts per minute/culture $\pm \mathrm{SE}$ of triplicate samples. 
Nucleoside-specific tolerance could be induced in vitro by incubating SLE lymphocytes with (A,G,C,T)HGG. Preincubation with A,G,C,T conjugated to HSA did not result in the suppression of anti-A,G,C,T response, indicating that not all conjugates of A,G,C,T to self antigens were necessarily tolerogenic. These results extended the observations on DNP specific tolerance induced by DNP-HGG to antigenic determinants relevant to autoimmunity in humans. ${ }^{2}$ Initially, in experimental animals, tolerance was induced in $(\mathrm{NZB} \times \mathrm{NZW}) \mathrm{F}_{1}$ mice by the administration of a synthetic nucleic acid plus cyclophosphamide (29). Subsequently, Borel et al. induced tolerance to DNA by treating $(\mathrm{NZB} \times \mathrm{NZW}) \mathrm{F}_{1}$ mice with conjugates of nucleoside coupled to isologous IgG (11). The prolonged administration of denatured DNA noncovalently complexed to poly D-lysine also prevented the appearance of antibody to denatured DNA (28). Similarly, successful induction of tolerance to nucleic acid determinants was induced by administration of nucleoside conjugates of D-GL (31).

It appears that the suppression of SLE antibody to nucleic acid antigens can now be achieved in vitro by inducing tolerance with nucleic acid linked to human IgG in cultured lymphocytes sensitized to nucleic acid antigen. Although DNA antigenic determinants larger than nucleosides are required to induce tolerance to DNA in SLE patients (32), the data suggests that an ongoing immune response can be influenced in vitro by inducing tolerance with nucleic acid linked to human IgG.

\section{ACKNOWLEDGMENTS}

The authors wish to thank Miss J. A. Distaso for her skillful technical assistance.

This work was supported by National Institutes of Health grants AI 12069, AI 13867, and CA 06516.

\section{REFERENCES}

1. Glass, D., and P. H. Schur. 1977. Autoimmunity and systemic lupus erythematosus. In Autoimmunity. $\mathbf{N}$. Talal, editor. Academic Press, Inc., New York. pp. 536568.

2. Tan, E. M., P. H. Schur, R. I. Carr, and H. G. Kunkel. 1966. Deoxyribonucleic acid (DNA) and antibodies to DNA in the serum of patients with systemic lupus erythematosus. J. Clin. Invest. 45: 1732-1740.

3. Koffler, D., R. K. Carr, V. Agnello, T. Fiezi, and H. G. Kunkel. 1969. Antibodies to polynucleotides: distribution in human serum. Science (Wash. DC). 166: 16481649.

4. Koffler, D., V. Agnello, R. Thoburn, and H. G. Kunkel. 1971. Systemic luypus erythematosus: prototype of im-

${ }^{2}$ Morimoto, C., J. A. Distaso, and Y. Borel. Submitted for publication. mune complex nephritis in man. J. Exp. Med. 134: 169s$179 \mathrm{~s}$.

5. Talal, N., A. D. Steinberg, and G. G. Daley. 1971. Inhibition of antibodies binding polyinasinic polycytidylic acid in human and mouse lupus sera by viral and synthetic ribonucleic acid. J. Clin. Invest. 50: 1248-1252.

6. Abdou, N. I., A. Sagawa, E. Pascal, J. Hevert, and S. Sadeghee. 1976. Suppressor T cell subnormality in idiopathic systemic lupus erythematosus. Clin. Immunol. Immunopathol. 6: 192-199.

7. Bresnihan, B., and H. E. Jasin. 1977. Suppressor function of peripheral blood mononuclear cells in normal individuals and patients with systemic lupus erythematosus. J. Clin. Invest. 59: 106-116.

8. Morimoto, C. 1978. Loss of suppressor T lymphocyte function in patients with SLE. Clin. Exp. Immunol. 32: 125-133.

9. Sakane, T., A. D. Steinberg, and I. Green. 1978. Studies of immune function of patients with SLE. I. Dysfunction of suppressor $T$ cell activity related to impaired generation of, rather than response to suppressor cells. Arthritis Rheum. 21: 657-664.

10. Sagawa, A., and N. I. Abodou. 1978. Suppressor cell dysfunction in systematic lupus erythematosus. Cells involved and in in vitro correction. J. Clin. Invest. 62: 786-796.

11. Borel, Y., R. M. Lewis, and B. D. Stollar. 1973. Prevention of murine lupus nephritis by carrier dependent induction of immunologic tolerance to denatured DNA. Science (Wash. DC). 182: 76-78.

12. Borel, Y., and M. Young. 1980. Nucleic acid specific suppressor T cells. Proc. Natl. Acad. Sci. USA. 77: 1593 1596.

13. Golan, D. T., and Y. Borel. 1971. Non-antigenicity and immunologic tolerance: the role of the carrier in the induction of tolerance to the hapten. J. Exp. Med. 134: 1046-1061.

14. Erlanger, B. F., and S. M. Beiser. 1964. Antibodies specific for ribonucleosides and their reaction with DNA Proc. Natl. Acad. Sci. USA. 52: 68-74.

15. Morimoto, C., E. L. Reinherz, and S. F. Schlossman 1981. Regulation of in vitro primary anti-DNP antibody production by functional subsets of $T$ lymphocytes in man. J. Immunol. 127: 69-73.

16. Morimoto, C., E. L. Reinherz, and S. F. Schlossman 1981. Primary in vitro anti-KLH antibody formation by PBL in man. J. Immunol. 127: 514-517.

17. Goldman, J. A., A. Litwin, L. E. Adams, R. C. Kruerger, and E. V. Hess. 1972. Cellular immunity to nuclear antigen in SLE. J. Clin. Invest. 51: 2669-2677.

18. Rosenthal, C. J., and E. C. Franklin. 1975. Depression of cellular mediated immunity in systemic lupus erythematosus. Arthritis Rheum. 18: 207-217.

19. Abe, T., M. Hara, K. Yamasaki, and M. Homma. 1973. Cell mediated immune response in systemic lupus erythematosus. Arthritis Rheum. 16: 688-694.

20. Jasin, H. E., and M. Ziff. 1975. Immunoglobin synthesis by peripheral blood cells in systemic lupus erythematosus. Arthritis Rheum. 18: 219-224.

21. Nies, K. M., and J. S. Louie. 1978. Impaired immunoglobulin synthesis by peripheral blood lymphocytes in systemic lupus erythematosus. Arthritis Rheum. 21: 5157.

22. Morimoto, C., E. L. Reinherz, L. M. Nadler, J. A. Distaso, A. D. Steinberg, and S. F. Schlossman. 1982. Comparison in $\mathrm{T}$ and $\mathrm{B}$ cell markers in patients with Sjogren 
syndrome and systemic lupus erythematosus. Clin. Immunol. Immunopathol. 22: 270-278.

23. Bankhurst, A. D., and R. C. Williams, Jr. 1975. Identification of DNA binding lymphocytes in patients with systemic lupus erythematosus. J. Clin. Invest. 56: 13781385.

24. Vaughan, J. H., and T. Chihara. 1973. Lymphocyte function in rheumatic disorders. Arch. Intern. Med. 135: 1324-1328.

25. Budman, D. R., E. B. Merchant, A. D. Steinberg, D. Doft, M. E. Gershwin, E. Lizzio, and J. P. Reeves. 1977. Increased spontaneous activity of antibody forming cells in the peripheral blood of patients with active SLE. Arthritis Rheum. 20: 829-833.

26. Morimoto, C., T. Abe, M. Hara, and M. Homma. 1977. In vitro TNP-specific antibody formation by peripheral lymphocytes from patients with systemic lupus erythematosus. Scand. J. Immunol. 6: 575-579.

27. Bobrove, A. M., and P. Miller. 1977. Depressed in vitro B lymphocyte differentiation in systemic lupus erythematosus. Arthritis Rheum. 20: 1326-1333.
28. Hoch, S., J. Schwaber, and P. H. Schur. 1982. Frequency of anti-DNA antibody producing cells from normals and patients with systemic lupus erythematosus. Arthritis Rheum. 25: 3s.

29. Steinberg, A. D., and N. Talal. 1970. Suppression of antibodies to nucleic acids with polyinosinic polycyticylic acid and cyclophosphamide in murine lupus. Clin. Exp. Immunol. 7: 687-691.

30. Parker, L. P., B. H. Hahn, and C. K. Osterland. 1974 Modification of NZB/NZW $F_{1}$ autoimmune disease by development of tolerance to DNA. J. Immunol. 113: 292-297.

31. Eshhar, Z., B. Benacerraf, and D. H. Katz. 1975. Induction of tolerance to nucleic acid determinants by administration of a complex of nucleoside D-glutamic acid and D lysine (D-GL). J. Immunol. 114: 872-876.

32. Papallian, M., E. Laffer, R. Wong, and B. D. Stollar. 1980. Reaction of systemic lupus erythematosus anti-native DNA antibodies with native DNA fragments from 20 to 1200 base pairs. J. Clin. Invest. 65: 469-477. 